\title{
Lessons learned: The longitudinal effects of Austria's labor market integration policies on Bosnian refugees
}

\author{
Isra Syed Hussain, Fulbright Combined Research Grantee \\ University of Vienna, Fulbright Austria 2018-19
}

\begin{abstract}
The response to the recent influx of refugees in Europe indicates a need to reevaluate systems of reception and integration in a global society that is marred by increased xenophobia and nationalist rhetoric. Nearly three decades ago, the Austrian government deployed special accommodations to handle a similarly sized influx of refugees entering Europe, individuals and families who were fleeing ethnic cleansing from the Bosnian War. These accommodations, and their eventual economic integration components, provide longitudinal data that indicates a system that allowed employment rates of Bosnian refugees to match the rate of host country populations within a generation.

Through thematic analysis of an extensive literature review and field consultations in Vienna, this research will investigate what lessons the global community can learn from Austria's treatment of Bosnians refugees, and whether these lessons can contribute to improved procedures for integrating refugees into host societies. Preliminary results indicate the role of social capital, civil society, and religion as factors of labor market integration, while also acknowledging rates of underemployment and stagnation in the asylum process as deterrents to positive relationship formation between host societies and refugee populations. The culmination of this year-long project will be a series of recommendations on how local and national actors can enact services that will benefit the longer-term goals of both refugee populations and host societies.
\end{abstract}




\section{Introduction}

The influx of Syrian refugees who arrived in Europe during years 2015-2017 led to a collapse of asylum systems throughout Europe, indicating the vast lack of preparation among European countries to handle crisis migration scenarios. Functioning in an emergency mode and hoarding asylum seekers into camps ignored long-term outcomes of this brisk response and undermined the many initiatives being carried out by civil society networks. Instead, asylum systems throughout Europe became overburdened, adding to an atmosphere of increased economic fears and xenophobia fueled by populist political parties.

From a historical perspective, the most efficient responses to refugee influxes have occurred when European states instead operated on a model of rapid integration. ${ }^{1}$ Ideally, in this scenario, governments and service providers work in conjunction with each other to provide basic needs that quickly transition into a more thorough integration process for refugees, including systems for education and entry into the labor market. ${ }^{2}$ Implementing effective integration measures would benefit not only the refugee population in question, but also the economy and overall stability of host countries.

The following research presents an investigation of longitudinal results of a state's integration policies towards refugees, focusing on long-term benefits to both the migrating population and host community. The Bosnian refugee population, arriving in Western Europe during the Bosnian War in the early 1990s and sharing several similarities to refugees seeking to integrate into European society today, has emerged as a trademark population when studying the longterm effects of integration. This research is a critical analysis of Austria's labor market integration services in terms of how the state and partnering organizations handled the influx of refugees during the 1990s. Are there aspects of these integration policies that could be replicated to current day refugee populations in order to phase out of crisis-mode policies and enact more sustainable, long-term solutions to migratory influxes?

\section{i. $\quad$ Measuring integration as a process}

Integration is difficult to define, which may reflect the subjective character of integration as a process. One persistent theory of integration, created by social psychologist John W. Berry in the late 1990s, defines an integration process as one in which new identities emerge as migrant

\footnotetext{
${ }^{1}$ Cheung, S.Y. \& Phillimore, J. (2013). Refugees, Social Capital, and Labour Market Integration in the UK. Sociology 48(3): 518-536.

2 Fyvie, A., Ager, A., Curley, G. and Korac, M. (2003). 'Integration mapping the field volume II: distilling policy lessons from the "mapping the field" exercise'. Home Office Online Report 29(3).
} 
groups and host societies change in conjunction with one another over time. ${ }^{3}$ Integration can also be conceptualized as a process through which migrants pass en route to assimilation, when an individual is interested in maintaining a balance between original culture and also taking part in daily interactions with members of the host community. In this definition, social networks are integral to the understanding of integration. ${ }^{4,5}$

The Office of the United Nations High Commission for Refugees (UNHCR) asserts that integration policies which allow all newcomers to become economically productive "lead to selfreliance, dignity, and social interaction and are beneficial to individuals and the receiving society", ${ }^{6}$ while a society with large, unproductive segments may become socially and economically segregated. The working definition of integration used in this research characterizes the process of integration as not only something that happens passively to an individual over time, but instead is a process where an individual and society actively and selectively control aspects of integration. ${ }^{7}$

The following research will rely on this notion of integration as a process, investigating social interactions, demographic qualities, and service provisions from government and nongovernmental providers as indicators and important dimensions to labor market integration, and overall integration, of refugees.

\section{ii. Introduction to labor market integration of refugees}

The largest influx of refugees in Europe since the breakup of Yugoslavia in the early 1990s occurred just recently, during the height of the Syrian refugee crisis. Official government calculations indicate that over 180,000 refugees applied for asylum in Austria between 2014 and 2017; of this population, over 70,000 were granted work permits. ${ }^{8}$ Despite access to work permits for nearly half of all asylum requestors, refugee unemployment remained high, with only $15.2 \%$ of those having received work permits in 2015 and 2016 in positions of legal employment. ${ }^{9}$

\footnotetext{
${ }^{3}$ Berry, J. W. (1997) Immigration, acculturation and adaptation. Applied Psychology: An International Review 46(1): 5-68.

${ }^{4}$ Ibid.

${ }^{5}$ Conversely, within migration literature, migrants become assimilated if they do not maintain social networks with individuals from their country of origin, separated if they do not create connections in their host country, or excluded if they have no social networks and become marginalized. (Campos, D. G. (2018). Living with Immigrants in a Context of Difference: Exclusion, Assimilation, or Pluralism. The Pluralist 13(2): 109-118.)

${ }^{6}$ United Nations High Commissioner for Refugees. (2013). A New Beginning: Refugee Integration in Europe, 10.

${ }^{7}$ Ibid.

${ }^{8}$ Eggenhofer-Rehart, P. M., Latzke, M., Pernkopf, K., Zellhofer, D., Mayrhofer, W., Steyrer, J. (2018). Refugees' career capital welcome? Afghan and Syrian refugee job seekers in Austria. Journal of Vocational Behavior, 105: 31 45.

${ }^{9}$ Ibid.
} 
Despite these low percentages, employment is continuously cited as a crucial factor for integration, for it not only allows economic stability for migrant families but it also improves knowledge about the host society and creates networks outside of migrants' immediate families. ${ }^{10}$

However, specific barriers exist for refugees who are attempting to enter the labor market which set them apart from typical migrant cases. Many refugees have lost or do not own identification documents and qualification certificates. Oftentimes, educational attainment and certifications from countries of origin are not accepted in host countries. Refugees may also have experienced long periods of inactivity and unemployment during the asylum process. Limited social networks, trauma, and anxiety over family separation may hinder motivation to seek new jobs. As a result, refugees frequently suffer from underemployment, including downward professional and social status. ${ }^{11}$ Though economic integration is vital to both refugees and host countries, barriers have and continue to exist for those who seek to swiftly enter the labor market and become productive members of society.

\section{iii. Historical context: Bosnian refugees' entry into Austria}

The difficulty of accessing the labor market in host countries points to the necessity of investigating alternative methods to workforce integration for this population. An analysis of Bosnian refugees entering Europe in the early 1990s allows society to look past "immediate integration outcomes and take a longer-term view"12 on integration services that worked well over time.

In order to understand the longer-term integration of Bosnians in Austria, it is important to recognize the initial landscape they faced upon entry in Austria. Following the breakup of Yugoslavia in the 1990s and the consequent ethnic cleansing of Muslim Bosniaks, over 1.2 million people fled Bosnia and Herzegovina as war refugees. ${ }^{13}$ About half of the displaced Bosnians fled to Western European countries, and due to geographical proximity, settled in and travelled through Austria. Between 1992 and 1994, 86,500 refugees from Bosnia and Herzegovina were registered in Austria, a total of $1.1 \%$ of the host country population. ${ }^{14}$ While refugee populations were typically inducted through guidelines of the 1951 Geneva Refugee convention, special accommodations were enacted for Bosnians that would not allow them to apply for convention asylum, the general consensus being that the Bosnian War would soon end

\footnotetext{
${ }^{10}$ Lundborg, P. (2013). Refugees' Employment Integration in Sweden: Cultural Distance and Labor Market Performance. Migration and Culture 21(2): 219-232.

${ }^{11}$ United Nations High Commissioner for Refugees. (2013). A New Beginning: Refugee Integration in Europe.

12 Barslund, M., Busse, M., Lenaerts, K., Ludolph, L., Renman, V. (2017). Integration of Refugees: Lessons from Bosnians in Five EU Countries. Leibniz Information Centre for Economics. Intereconomics, 52(5): 257.

13 Ibid.

14 Ibid.
} 
and refugees could return home. Because of this assumption, special temporary protected status (TPS) was enacted with a 'de facto' suspension of asylum for Bosnian refugees.

If Bosnians had been granted asylum initially, then they could have moved freely to any area within Austria, worked legally, and used the federal employment agency's service to find jobs. However, the Österreichs Bund-Länder Aktion, a federal-provincial relief scheme, was enacted to allow Bosnians to bypass many of the administrative roadblocks other refugee populations faced in the asylum process through TPS. Through this scheme, displaced Bosnians could register with Austrian officials in exchange for food, health care, and for those placed in public housing, cash payments, services which were often administered through partnering organizations. Finances for these services were shared by the Ministry of the Interior and the different provinces.

This scheme, however, did not allow initial access into the labor market. There is a dearth of literature on the role of the black labor market, the Schwarzarbeit, in this time period, but economic conditions indicate that many Bosnian refugees had access to this informal, illegal employment through co-ethnic contacts.

In 1995, Bosnian war refugees finally began being granted work permits to find legal employment in Austria through the updated Bund-Länder Aktion. However, the highly regulated Austrian labor market allocated very limited number of work permits to be issued to Bosnian de facto refugees. Austria had instituted a yearly fixed quota for work permits in 1990 to protect the local workforce, which also applied to Bosnians. ${ }^{15}$

In 1998, the Bosniergesetz, the 'Bosnians Law', regulated the transformation of the Bosnian refugees' de facto status into permanent residence status. Under certain conditions, such as proof of legal employment or source of income, this status was transformed into guest-worker status where Bosnians could be granted Beschäftigungsbewilligungen, or special work permits, that allowed them to legally work. ${ }^{16}$

There is general disagreement about whether the special accommodations Bosnians faced through TPS and their 'de facto' status hindered or benefitted the initial integration of this population. In many accounts, the accommodations allowed Bosnians to bypass many restrictions that convention refugees faced by providing housing subsidies and granting large numbers of work permits to refugees in 1995. On the other hand, the Bund-Länder Aktion

\footnotetext{
${ }^{15}$ European Migration Network \& International Organization for Migration. (2004). The Impact of Immigration on Austria's Society: A Survey of Recent Austrian Migration Research. The Impact of Immigration on Europe's Societies: Budget year 2003.

${ }^{16}$ Franz, B. (2005). Uprooted \& Unwanted: Bosnian Refugees in Austria and the United States. New York, New York: Texas A\&M University Press College Station.
} 
provided basic amenities but blocked access to legal employment for several years, forcing Bosnians to be reliant on provincial aid and tempting them to access illegal systems of employment. This debate will be addressed during the field investigation component of this research project.

\section{iv. Purpose of study}

The question emerges: were tactics employed to allow the swift entry of Bosnians into Austrian society successful in the long term, and if so, can these longitudinal results have any influence on current day policies?

There are some positive aspects of the current refugee situation to consider while investigating this question. In interviews of refugee attitudes toward integration in Austria in 2015, BuberEnnser and colleagues found that $67 \%$ of respondents intended to "search for a job" after having been granted official asylum status, indicating a high intention to participate in the host society's labor market. An overwhelming majority of refugees (72\%) also report having worked in their home country's labor market in the past, ${ }^{17}$ therefore entering the Austrian labor market with previous skills and professional experience.

An eagerness to integrate into the labor market would provide numerous benefits to the host country. Effective participation by refugees and asylum seekers in the labor market of the host society is considered to be a key indicator of integration ${ }^{18}$, and rapid integration of refugees into the labor market of Western European countries will help to "counter some of the adverse fiscal effects of population aging", ${ }^{19}$ while simultaneously helping to reduce the fiscal costs associated with the most recent inflow of refugees from the Middle East. ${ }^{20}$

This study aims to provide support and recommendations for policies that initiate the rapid integration of asylum seekers into host societies, based on results and perspectives of Austria's policies to integrate Bosnians in the 1990s, to counter any adverse effects of delayed asylum procedures and to promote cost-effective solutions that benefit both refugees and host communities.

\footnotetext{
17 Buber-Ennser, I., Kohlenberger, J., Rengs, B., Al Zalak, Z., Goujon, A., Striessnig, E., Lutz, W. (2016). Human capital, values and attitudes of persons seeking refuge in Austria in 2015. PLoS One, 11(9).

${ }^{18}$ UNHCR. A new beginning: Refugee integration in Europe. Geneva: The UN Refugee Agency; 2013.

${ }^{19}$ Aiyar, S., Barkbu, B., Batini, N., Berger, H., Detragiache, E., Dizioli, A. et al. (2016). The refugee surge in Europe: Economic challenges. Washington DC: International Monetary Fund.

${ }^{20}$ Organization for Economic Cooperation and Development. (2016). Making integration work: Refugees and others in need of protection. Paris: OECD Publishing.
} 


\section{Methods}

Though there were still existing roadblocks and results indicating large scale underemployment, the tactics used by Austrian service providers to integrate Bosnian refugees into the labor market had successes which have the potential for benefitting current day refugee populations. This research will analyze the longitudinal effects of Austria's labor integration policies and services that were implemented for Bosnian Muslims in the 1990s, and the themes and lessons learned that are applicable to the current landscape of refugee integration.

This project design will include a review of existing literature and a field research component, comprising of perspectives of key informants working within government and other serviceproviding organizations in Vienna. The consultations will be structured as guided interviews, indicating that questions may shift so as to account for different areas of focus by interview subjects.

For this reason, manipulated variables are not defined through this work. Instead, a series of key questions will be employed throughout interviews relating to the overarching research question. These key questions explore the history of service provision for refugees and the current day landscape of refugees entering the workforce, based on each interviewee's experiences and expertise:

- What were the advantages and disadvantages of initial integration policies to help Bosnian refugees enter the Austrian workforce in the 1990s?

- How is the integration of Bosnian refugees perceived today? Have Austrian policies of employment integration had longitudinal success?

- What is the current landscape of service provision for refugees in Austria? Are there aspects of past policies that could be applied for the labor market integration of today's refugee population?

\section{i. $\quad$ Research Sample and Participants}

The primary sources for interviews are experts who work within organizations in Vienna that provide services to refugees. Organizations of interest include contractors through the Austrian government, nongovernmental organizations, and religiously affiliated organizations. This research will portray as complete of a picture of services as possible by locating the sample population within the specific realm of immigration services, but with a variety of disciplines and roles. 


\section{ii. $\quad$ Data Collection Tools}

Primary semi-structured (guided) interviews are being conducted to collect data in conjunction with a comprehensive review of existing literature. Interviews last between 60 and 90 minutes and occur throughout the city of Vienna. Interviews are audio recorded and transcribed.

\section{iii. Data Analysis}

Framework analysis, with a thematic analysis of content, is being employed in order to identify and categorize recurrent or common themes. This analysis consists of a number of stages that include familiarization with the transcribed interviews, indexing key themes and sub themes, charting, and mapping. The audio accounts of the interviews are transcribed, and the transcripts are then read and reread in order to ensure familiarity with the accounts and to maintain an understanding of context. Following this, thematic analyses of the transcripts are conducted, with the assistance of NVivo 12 for Mac (QSR International) for identification and documentation purposes.

\section{Introduction to thematic discussion on research findings}

Several themes have emerged from the initial review of literature and several primary consultations. These themes will be discussed in greater length in upcoming months with evidence to support the importance and practicality of each component of integration, with the goal of providing a clearer image of the landscape of historic and current day policies employed in Austria to help refugees integrate into society. The initial identified themes are as follows:

\section{i. Labor market integration, underemployment, and the role of the Schwarzarbeit}

Austria indicated very positive results of labor market integration of Bosnians early on: the employment rate for Bosnians had reached 64\% in 1998, only 20 percentage points away from the native population. By 2008, this gap had closed in Austria, though it is important to note that there is a $10 \%$ difference in employment rates when disaggregated for gender (females are at a greater disadvantage) for Bosnians as compared to Austria's native population ${ }^{21}$.

However, publicly available employment results do not specify the level of employment Bosnians achieved, and whether this employment matched their educational and skills level. Evidence may suggest that though Bosnians gained access to the labor market within just several

${ }^{21}$ Organization for Economic Cooperation and Development. (2016). Making integration work: Refugees and others in need of protection. Paris: OECD Publishing. 
years of arrival, the initial gap in receiving work permits forced refugees into illegal forms of employment; and once legally employed, Bosnians were relatively underemployed as compared to the native Austrian population ${ }^{22}$. How does underemployment of Bosnian refugees compare to the current and future underemployment rates of today's refugee populations in Vienna? And how does gender factor into opportunities for employment integration?

\section{ii. Social capital as a factor of integration}

Social capital continues to be used as an indicator of migrant integration and success in host country analyses. For the purposes of this research, social capital is defined as "the collection of resources owned by the members of an individual's personal social network which may become available to the individual". ${ }^{23}$ Oftentimes, capital forms for refugees may be strongly devalued upon entry in the host country, especially once refugees encounter unfamiliar labor market rules and status $\operatorname{loss}^{24}$. Therefore, it is important to distinguish between the actual value of prior capital and the need to develop capital, especially social capital, which is relevant within host country societies. This research will focus on bonding and bridging social capital in order to unearth the advantages and disadvantages of developing distinct social connections in refugees' initial integration.

\section{iii. Civil society and service enhancement}

Though migration policies are the responsibility of national governments, the concentration of migrants in metropolitan areas give local governments and organizations the unique ability to structure administrative and financial frameworks that enact location-specific policies for migrant integration. Interviewees have suggested the important yet generally undocumented role that civil society also played in welcoming Bosnians to Vienna in the 1990s. And since 2015, Vienna has once again become part of a global network of municipalities that are supporting refugees and the many opportunities they bring. Despite budget cuts at the national level, the city of Vienna has continued to support refugees and NGOs seeking to assist refugees from its own budget and additional European Union funds. This financial aid has contributed to peer mentoring programs for refugees and groups where refugees study in order to re-qualify in their professional discipline in order to join the Austrian workforce in their appropriate fields. ${ }^{25}$ Expert consultations throughout the city of Vienna will add to the growing recognition of the role of

\footnotetext{
22 Buber-Ennser, I., Kohlenberger, J., Rengs, B., Al Zalak, Z., Goujon, A., Striessnig, E., Lutz, W. (2016). Human capital, values and attitudes of persons seeking refuge in Austria in 2015. PLoS One, 11(9).

${ }^{23}$ Gericke, D., Burmeister, A., Löwe, J., Deller, J., \& Pundt, L. (2018). How do refugees use their social capital for successful labor market integration? An exploratory analysis in Germany. Journal of Vocational Behavior, 105: 48.

${ }^{24}$ Eggenhofer-Rehart, P. M., Latzke, M., Pernkopf, K., Zellhofer, D., Mayrhofer, W., Steyrer, J. (2018). Refugees' career capital welcome? Afghan and Syrian refugee job seekers in Austria. Journal of Vocational Behavior, 105: 3145.

${ }^{25}$ Womack, H. (2018). Vienna learns the benefit of giving warm welcome to refugees. United Nations High Commissioner for Refugees.
} 
civil society in integrating refugees, as well as proposed insights into how the relationship between local and national governments can be restructured to ensure continued flow of funds to service providing organizations.

\section{iv. $\quad$ Religion and the State: A mediating factor for improved public perception}

In terms of the current day refugee population, critics point to the role of their religious affiliation as a major roadblock in successful integration into European societies. However, Islam has been officially recognized as a religion in Austria since 1912, ${ }^{26}$ and the Islamische Glaubensgemeinschaft in Österreich, the Islamic Community in Austria, was recognized as the official representation of all Muslims residing in the country in 1979. Since then, it has been part of the legal framework of Austria and granted the same status as other recognized religions.

Despite this legal recognition, the understanding that religion, and specifically Islam, indeed plays a factor into societal isolation and integration factors remains important. This project aims to investigate how an increased collaboration between state actors and the Muslim community may benefit public perception and the labor and societal integration of this religious group, increasing visibility of their commitment to integration while maintaining their own religious identities without fear of ostracization.

\section{Concluding recommendations}

Among current integration literature, there are a collection of published recommendations for policy makers to improve the system of integration into the labor market. Researcher Eggenhofer-Rehart and colleagues summarize these recommendations in their 2018 report, ${ }^{27}$ which include expedited certification approvals and familiarity with foreign certifications; publicly-sponsored internships as a stepping stone into regular employment; and comprehensive training in local job search practices and trade license acquisition for refugees, organized through a country's labor market services division.

These common recommendations, however, do not consider one of the root problems of the integration process: formal employment opportunities and government-sourced trainings remain inaccessible to refugees until asylum procedures have been completed. The uncertain length of

${ }^{26}$ Norris, Pippa, Inglehart, R. (2012). Muslim integration into Western cultures: Between origins and destinations. Political Studies 60: 228-51.

${ }^{27}$ Eggenhofer-Rehart, P. M., Latzke, M., Pernkopf, K., Zellhofer, D., Mayrhofer, W., Steyrer, J. (2018). Refugees' career capital welcome? Afghan and Syrian refugee job seekers in Austria. Journal of Vocational Behavior, 105: 3145. 
asylum proceedings forces asylum seekers to rely on state-sponsored assistance and the black market for labor integration in the interim. This interim time period speaks to the need for a restructuring of asylum and refugee employment opportunities, to allow for more swift resettlement options and smaller service requirements by the state, consequently preventing overburdened asylum systems. Though the TPS program for Bosnian refugees has sparked controversial discussion, the general idea that special provisions could be made to accelerate the integration process may be valid to handle a large influx of refugees. This solution will be investigated further to better understand the merits of an accommodation system to bypass the bureaucracy tied to lengthy asylum procedures.

Austria's procedures for Bosnian refugees in the 1990s, albeit imperfect, indicate that it is possible to make special accommodations for asylum seekers outside of administrative norms for migration, in order for the host country to more effectively manage the high number of asylum applications and not suffer from a stagnant economic workflow. These accommodations would also benefit the individual asylum seekers. When planned in conjunction with refugees' preexisting qualifications and social capital, and with an openness to their unique cultural and religious identities, these services may positively affect the overall relationship between host societies and the refugee populations residing within them.

Upcoming results will investigate what lessons, if any, the global community can learn from Austria's treatment of Bosnian refugees. The culmination of this year-long project will be a series of recommendations derived from extensive literature and field research on how society can improve procedures for integrating refugees into host societies. 


\section{References}

Aiyar, S., Barkbu, B., Batini, N., Berger, H., Detragiache, E., Dizioli, A. et al. (2016). The refugee surge in Europe: Economic challenges. Washington DC: International Monetary Fund.

Barslund, M., Busse, M., Lenaerts, K., Ludolph, L., Renman, V. (2017). Integration of Refugees: Lessons from Bosnians in Five EU Countries. Leibniz Information Centre for Economics. Intereconomics, 52(5): 257.

Berry, J. W. (1997) Immigration, acculturation and adaptation. Applied Psychology: An International Review 46(1): 5-68.

Buber-Ennser, I., Kohlenberger, J., Rengs, B., Al Zalak, Z., Goujon, A., Striessnig, E., Lutz, W. (2016). Human capital, values and attitudes of persons seeking refuge in Austria in 2015. PLoS One, 11(9).

Campos, D. G. (2018). Living with Immigrants in a Context of Difference: Exclusion, Assimilation, or Pluralism. The Pluralist 13(2): 109-118.)

Cheung, S.Y. \& Phillimore, J. (2013). Refugees, Social Capital, and Labour Market Integration in the UK. Sociology 48(3): 518-536.

Eggenhofer-Rehart, P. M., Latzke, M., Pernkopf, K., Zellhofer, D., Mayrhofer, W., Steyrer, J. (2018). Refugees' career capital welcome? Afghan and Syrian refugee job seekers in Austria. Journal of Vocational Behavior, 105: 31-45.

European Migration Network \& International Organization for Migration. (2004). The Impact of Immigration on Austria's Society: A Survey of Recent Austrian Migration Research. The Impact of Immigration on Europe's Societies: Budget year 2003.

Franz, B. (2005). Uprooted \& Unwanted: Bosnian Refugees in Austria and the United States. New York, New York: Texas A\&M University Press College Station.

Fyvie, A., Ager, A., Curley, G. and Korac, M. (2003). 'Integration mapping the field volume II: distilling policy lessons from the "mapping the field" exercise'. Home Office Online Report 29(3).

Gericke, D., Burmeister, A., Löwe, J., Deller, J., \& Pundt, L. (2018). How do refugees use their social capital for successful labor market integration? An exploratory analysis in Germany. Journal of Vocational Behavior, 105: 48. 
Lundborg, P. (2013). Refugees' Employment Integration in Sweden: Cultural Distance and Labor Market Performance. Migration and Culture 21(2): 219-232.

Norris, Pippa, Inglehart, R. (2012). Muslim integration into Western cultures: Between origins and destinations. Political Studies 60: 228-51.

Organization for Economic Cooperation and Development. (2016). Making integration work: Refugees and others in need of protection. Paris: OECD Publishing.

United Nations High Commissioner for Refugees. (2013). A New Beginning: Refugee Integration in Europe, 10.

Womack, H. (2018). Vienna learns the benefit of giving warm welcome to refugees. United Nations High Commissioner for Refugees. 